\title{
Closed reduction with traction for developmental dysplasia of the hip in children aged between one and five years
}

\author{
V. Rampal, \\ M. Sabourin, \\ E. Erdeneshoo, \\ G. Koureas, \\ R. Seringe, \\ P. Wicart
}

From the SaintVincent-de-Paul Hospital, Paris, France

\footnotetext{
V. Rampal, MD, Orthopaedic Surgeon

Service d'orthopedie pédiatrique

Hopital Saint Vincent-de-Paul, 74-82 avenue Denfert

Rochereau, 75014 Paris, France.

M. Sabourin, MD, Orthopaedic Surgeon

E. Erdeneshoo, MD,

Orthopaedic Surgeon

R. Seringe, MD, Professor,

Head of Service

P. Wicart, Professor

Department of Pediatric

Orthopaedic Surgery (APHP)

René Descartes University

(Paris V), Saint-Vincent-de-Paul

Hospital, 74-82 avenue Denfert-

Rochereau, 75674 Paris Cedex

14, France.

a. Koureas, $\mathrm{MD}, \mathrm{PhD}$

Orthopaedic Surgeon

Kokkinou 12-14 Zaimi Street, TK

27100 Pyrgos, Ilias, Greece.

Correspondence should be sent to Professor P. Wicart; e-mail: p.wicart@svp.aphp.fr
}

(C)2008 British Editorial Society of Bone and Joint Surgery doi:10.1302/0301-620X.90B7. $20041 \$ 2.00$

$J$ Bone Joint Surg [Br] 2008;90-B:858-63. Received 2 August 2007; Accepted after revision 20 March 2008

The treatment of developmental dysplasia of the hip diagnosed after the first year of life remains controversial. A series of 36 children ( $47 \mathrm{hips}$ ), aged between one and 4.9 years underwent gradual closed reduction using the Petit-Morel method. A pelvic osteotomy was required in $\mathbf{4 3}$ hips (91.5\%). The patients whose hips did not require pelvic osteotomy were among the youngest. The mean age at final follow-up was 16.1 years (11.3 to 32 ). The mean follow-up was 14.3 years ( 10 to 30 ).

At the latest follow-up, 44 hips (93.6\%) were graded as excellent or good according to the Severin classification. Closed reduction failed in only two hips $(4.3 \%)$ which then required open reduction. Mild avascular necrosis was observed in one (2.1\%).

The accuracy of the reduction and associated low complication rate justify the use of the Petit-Morel technique as the treatment of choice for developmental dysplasia of the hip in patients aged between one and five years.

Neonatal screening has allowed the diagnosis and treatment of children with developmental dysplasia of the hip (DDH) to be performed at an early age. Nevertheless, late diagnosis of DDH still occurs. ${ }^{1}$ Although open reduction is the treatment of choice when the diagnosis is made after the age of five years, ${ }^{2}$ the management of patients aged between one and five years remains controversial and may include closed or open reduction.

The techniques used for closed reduction have evolved considerably over the past 50 years. The original method developed by Somerville and $\mathrm{Scott}^{3}$ involved preliminary traction and subsequent open reduction with a derotational osteotomy of the femur. Beginning in the 1950s, Petit, Queneau and Borde ${ }^{4}$ combined preliminary traction and early closed reduction with derotational osteotomy of the femur. In the 1970 s, Morel ${ }^{5}$ proposed abduction of the hip and internal rotation with traction as a means of obtaining an atraumatic gradual 'descent' of the femoral head to the level of the acetabulum. Then, a hip spica cast was applied without general anaesthesia in order to achieve a concentric reduction of the femoral head into the acetabulum, as described by Severin. ${ }^{6}$ This protocol, termed the PetitMorel technique, has been in use at our institution since 1970 . The only deviation from the original method is that we apply the hip spica cast under general anaesthesia.
Our aim was to analyse the results of the Petit-Morel technique for treatment of DDH in patients aged between one and five years.

\section{Patients and Methods}

We included patients treated for idiopathic DDH between 1975 and 2000 at our institution who were aged between one and five years when treatment began. Children with a history of any previous treatment were excluded. A series of 80 consecutive children (94 hips) was treated during this period. Because of inadequate follow-up 20 children were excluded, leaving 60 (72 hips) with a minimum follow-up of five years. A follow-up for longer than ten years was available for 36 children (31 girls, five boys; 47 hips) and they formed the basis of the present study. Bilateral DDH had been diagnosed in 11 patients. The mean age at the onset of treatment was 1.9 years (1 to 4.9). According to the classification system of Gibson and Benson ${ }^{7} 20$ hips (42.5\%) were rated as having high subluxation (Fig. 1), 24 $(51.1 \%)$ medium and three $(6.4 \%)$ low subluxation. The mean follow-up was 14.3 years (10 to 30 ). The mean age at final follow-up was 16.1 years (11.3 to 32 ).

Technique of closed reduction. The aim of the first stage was to achieve the descent of the femoral head. To this end the child was fitted with a Berck harness (Sté FAG Medical SAS, St Georges de Reneins, France) which was fixed 


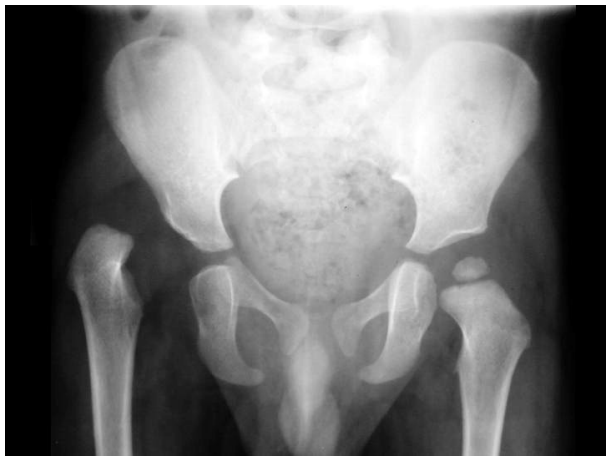

Fig. 1

Radiograph showing high developmental dysplasia of the right hip in a two-year-old boy.

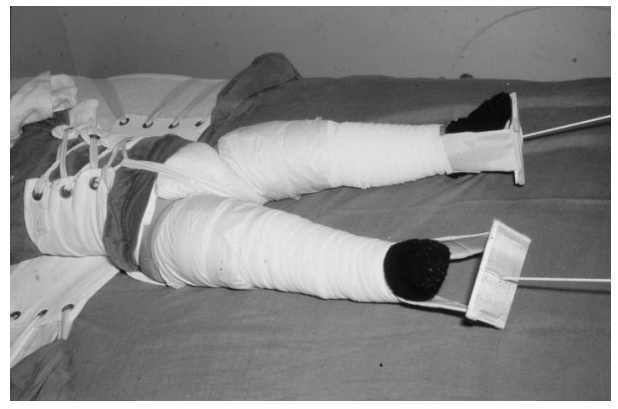

Fig. 2

Photograph showing the first stage of closed reduction. Bilateral skin traction is applied with the hips in extension.

to the bed. Bilateral longitudinal skin traction was then applied with the hips in extension (Fig. 2). Horizontal traction only was adequate because the iliopsoas tendon was already stretched by the adoptive stance and gait demonstrated by these patients. The initial weight used for traction, which corresponded to $10 \%$ of the body-weight, was gradually increased depending on the child's weight (up to $50 \%$ of their body-weight on each limb) and the degree of migration of the femoral head assessed on weekly radiographs. When the ossific nucleus was at the level of Hilgenreiner's line, ${ }^{8}$ progressive abduction $\left(30^{\circ}\right.$ to $\left.50^{\circ}\right)$ and internal rotation equal to the femoral anteversion were applied in order to render the proximal femoral metaphysis horizontal and orientate the epiphysis towards the triradiate cartilage (Fig. 3). In patients where the ossific nucleus was not radiologically visible, the appropriate time for beginning abduction was when Shenton's line had been restored on the radiographs. The amount of traction was then gradually reduced to allow for reduction of the femoral head into the acetabulum. The mean duration of trac-

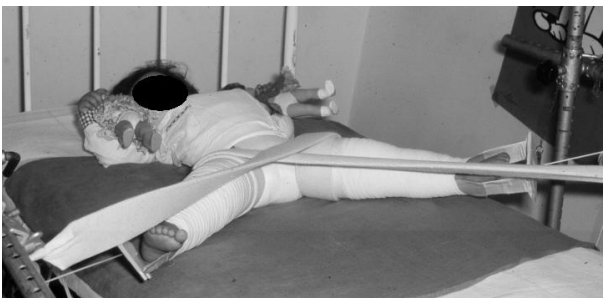

Fig. 3

Photograph showing abduction and internal rotation of the hip in order to orientate the proximal femur towards the triradiate cartilage.

tion was 5.4 weeks (3 to 10 ). Longer durations (6 to 10 weeks) were used until 1980. The shortest durations (three weeks) were observed in the younger children (1.0 to 1.5 years old).

The second stage consisted of the stabilisation of the 'presented' femoral head (Fig. 4a), in order to allow its progressive 'seating' into the acetabulum and a spontaneous definitive concentric reduction (Fig. 4b). A hip spica cast was applied under general anaesthesia in the reduced position $\left(20^{\circ}\right.$ flexion, $45^{\circ}$ abduction and slight internal rotation) obtained at the end of the traction stage. Two successive casts, spaced three months apart, were applied. The cast was worn for a mean period of 21 weeks ( 12 to 30).

The third stage, used for 43 hips $(91.5 \%)$, consisted of the operative management of residual acetabular dysplasia by a pelvic osteotomy ${ }^{9}$ which, in the early years of our experience, was performed in conjunction with a femoral ${ }^{10}$ osteotomy (Fig. 5).

Evaluation. The functional results were assessed by the use of the Merle d'Aubigné scoring system ${ }^{11}$ which includes separate evaluations of pain, range of movement and gait. Each subscore was rated on a 1- (worst) to 6- (best) point scale. The overall score was then classified as excellent (16 to 18$)$, good (13 to 15$)$, fair $(9$ to 12 ) or poor $(<9)$.

The anteroposterior (AP) pelvic radiographs were evaluated using the Severin grading system ${ }^{12}$ (Table I). The presence of growth disturbance or avascular necrosis of the proximal femur, was determined using the systems of Kalamchi and MacEwen ${ }^{13}$ and Bucholz and Odgen. ${ }^{14}$

Statistical analysis. The effect of age, gender and the severity of the dislocation on the final results was investigated using Fisher's exact test. A p-value $\leq 0.05$ was considered to be statistically significant.

\section{Results}

At the final follow-up all patients had satisfactory functional results, were free of pain, walked without a limp, and demonstrated flexion of the hip $>90^{\circ}$. No flexion contracture or other abnormal static or dynamic position was observed. 


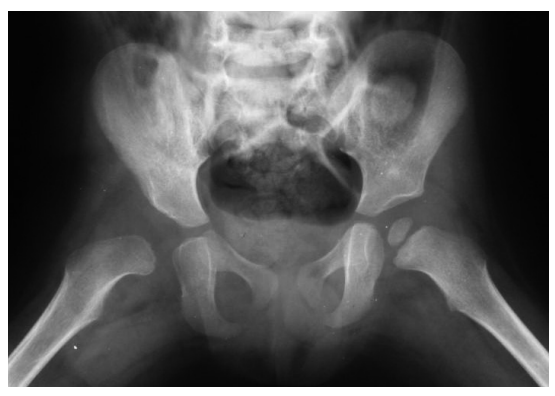

Fig. 4a

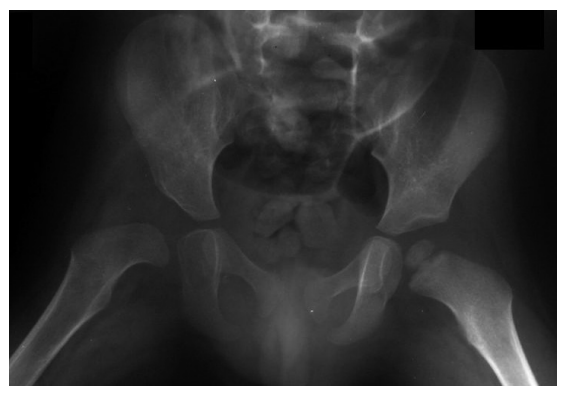

Fig. $4 b$

Anteroposterior pelvic radiographs a) after 25 days of traction, showing that the right hip of the same patient as in Figure 1 has descended and is 'presented' in front of the acetabulum. The patient is now ready for the application of the first spica cast and b) showing that the right hip is now in close relation to the acetabulum ('penetration') and the patient is ready for the second spica cast.

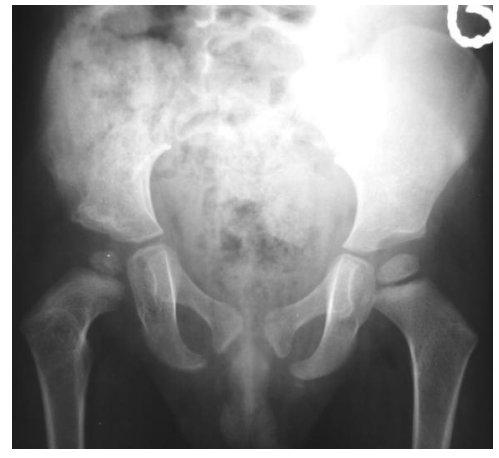

Fig. 5

Anteroposterior pelvic radiograph of the same patient as in Figure 1 at the age of three years, after a Salter pelvic osteotomy of the right hip.

Table I. The Severin ${ }^{12}$ radiological grading system for evaluation of the treatment of developmental dysplasia of the hip

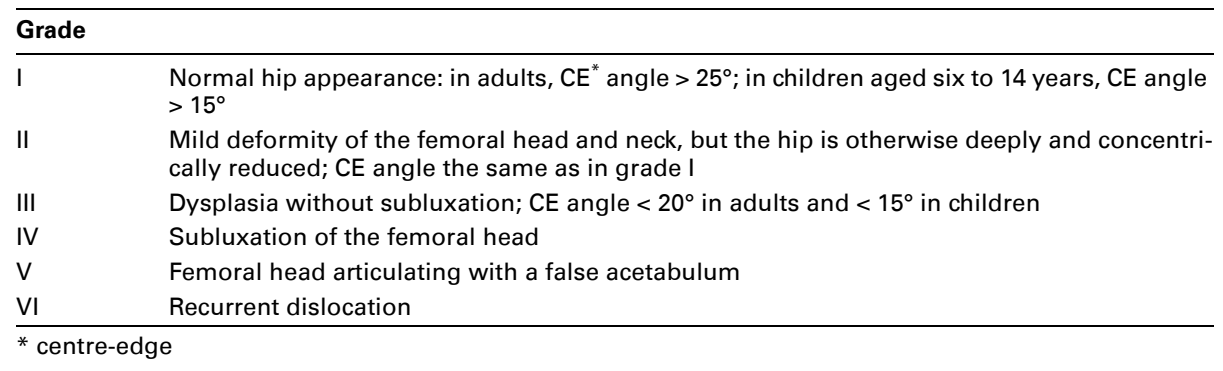

Radiologically, $44(93.6 \%)$ of the 47 hips were rated as normal or mildly deformed (Severin grade I or II) (Fig. 6, Table II). There were no hips in Severin grades V or VI.

There was only one hip $(2.1 \%)$ with avascular necrosis, which occurred after a failed closed reduction. This was followed by an open reduction. This lesion was rated as grade I according to both Kalamchi and MacEwen ${ }^{13}$ and Bucholz and Ogden ${ }^{14}$ and led to a secondary coxa magna, although the sphericity of the ossific nucleus was retained.

Young age at the onset of treatment significantly influenced the outcome. The results were better for children treated between one and three years of age (Table III). Overall, 40 hips (97.6\%) treated before the age of three were normal or mildly deformed at their last follow-up, compared with four hips $(66 \%)$ treated after this age $(\mathrm{p}<0.05)$. Gender was not a significant prognostic factor $(\mathrm{p}=0.48)$. The five hips of boys were rated as Severin grade I at the last review. Among the girls, 38 of 42 hips $(90.5 \%)$ were rated as Severin grade I or II. The severity of the disease did not affect prognosis $(\mathrm{p}=0.75)$. Of the hips initially classified as high, medium or low dislocations, 95\% (19 hips), 92\% (22 hips) and $100 \%$ (3 hips) were allocated as Severin grade I or II at their final follow-up, respectively $(\mathrm{p}=0.75)$.
Failure of closed reduction occurred in two hips $(4.3 \%)$. In both, we were unable to achieve penetration of the femoral head into the acetabulum, despite a satisfactory presentation. Subsequent open reduction showed intraarticular hindrances, an inverted limbus in one hip and a plica of the inferior capsule with a prominent acetabular transverse ligament in the other. The final radiological result for these hips was Severin grades I and II, respectively.

A Salter pelvic osteotomy ${ }^{9}$ was required in 43 hips $(91.5 \%)$ for the treatment of residual acetabular dysplasia. In the four $(8.5 \%)$ which did not require this procedure, the mean age of the patients at presentation was 15 months (12 to 20). This was lower than that of the patient group as a whole (23 months) ( $\mathrm{p}=0.001)$. Three of these four hips were graded as Severin I at the final follow-up. The fourth was classified as Severin grade IV, after refusal of a pelvic osteotomy by the family. In seven hips $(14.9 \%)$ a pelvic osteotomy was combined with osteotomy of the femur. In six, a pure derotational femoral osteotomy was performed and in one a varus-derotation femoral osteotomy. These hips were graded as Severin grade I and II in four and three hips, respectively. 


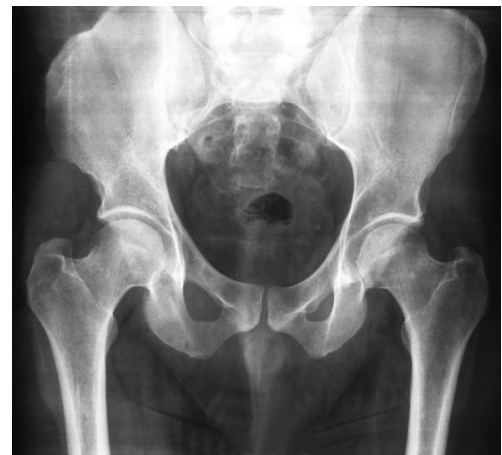

Fig. 6

Anteroposterior pelvic radiograph of the same patient as in Figure 1 at the age of 30 years. The right hip is graded as Severin I.

Complications were minor and included a superficial pin-track infection in two hips around the wires used for the fixation of the pelvic osteotomies and one case of an osteopenic tibial fracture after removal of the spica cast. This was treated by non-weight-bearing. The use of traction and the spica cast did not cause any skin complications.

\section{Discussion}

Previous studies on the treatment of DDH have given excellent or good outcomes (Severin grade I or II) in between $53 \%$ and $74 \%$ of cases ${ }^{15,16}$ without the use of preliminary traction, and between $36 \%$ and $82 \%$ after preliminary traction (Table IV). ${ }^{17,18}$ Thus, it is possible that preliminary traction does improve congruency of the hip. The hips with fair results were often characterised by residual acetabular dysplasia $^{9,15,17,19}$ which might be attributed to the limited adjunctive use of pelvic osteotomy. Morel $^{5}$ reported excellent/good results with this technique of gradual closed reduction in $85.4 \%$ of patients. Using the same technique we achieved an excellent/good outcome rate of $93.6 \%$ which, to our knowledge, is the highest reported rate after closed reduction. Gradual reduction seems to be the most effective technique of closed reduction in terms of optimising congruency of the hip.

Excellent or good outcome rates after open reduction have varied between $20 \%{ }^{17}$ and $100 \%{ }^{20}$ The best reported results $(93.6 \%$ to $100 \%), 9,21,22$ obtained after open reduction combined with a pelvic osteotomy and femoral shortening, are comparable with our findings. It appears that, on the basis of these studies, ${ }^{9,21,22}$ closed cannot be favoured over open reduction. However, the Severin score is a subjective outcome measure. For example, we believe that Figure $2 \mathrm{~b}$ ( $\mathrm{p} 415$ ) included in the report by Berkeley et $\mathrm{al}^{21}$ should have been allocated to Severin grade III, rather than to grade II. The need for a modification of the Severin score has been addressed by Robert and Seringe. ${ }^{23}$
Table II. Radiological findings based on the Severin ${ }^{12}$ grading system, at a minimum follow-up of ten years

\begin{tabular}{lr}
\hline Severin grade & Number of hips (\%) \\
\hline I & $43(91.5)$ \\
II & $1(2.1)$ \\
III & $1(2.1)$ \\
IV & $2(4.3)$ \\
V & $0(0.0)$ \\
VI & $0(0.0)$ \\
Total number of hips & 47 \\
\hline
\end{tabular}

A failure of reduction of $9.7 \%$ after progressive closed reduction has been reported. ${ }^{5}$ This was observed in only two $(4.3 \%)$ of our patients. Failure of reduction in DDH occurs more frequently after acute closed reduction, and varies to between $5.9 \%$ and $25 \%$ of cases. ${ }^{7,22,24,25}$ Furthermore, a recurrent dislocation may be observed after open reduction, with a reported incidence of up to $5.6 \% .^{10,17,21,22,25-28}$ It seems that the efficiency of closed reduction in preventing recurrent dislocation compares favourably with open reduction. However, after a failed first attempt a repeat open reduction is mandatory and is technically difficult, often leading to a poor outcome. Avascular necrosis developed in more than half of hips and onethird $^{10}$ were graded as Severin III or worse ${ }^{29}$ after repeat open reduction. Angliss et $\mathrm{al}^{17}$ reported that the rate of osteoarthritis at long-term follow-up was $25 \%$ after closed and $49 \%$ after open reduction. Based on these data, the survivorship rate at 45 years after open reduction (with the endpoint defined as a need for total hip replacement) was $54 \%$, demonstrating a dramatic decrease after the age of 30 years. $^{30}$

If closed reduction is performed after the age of 18 months, the likelihood of spontaneous correction of dysplasia $^{31}$ is decreased. ${ }^{7,10,32,33}$ Before the use of pelvic osteotomy for open reduction of dislocated hips, ${ }^{1}$ a varus derotational osteotomy of the femur was routinely used, but in fact failed to achieve correction of acetabular dysplasia. ${ }^{7,9,15,16,19}$ The Salter pelvic osteotomy, which successfully replaced femoral osteotomy, is an integral part of the Petit-Morel method. In six hips, treated during our transition period from using femoral to pelvic osteotomy, both procedures were undertaken. After 1980 we exclusively used pelvic osteotomy in those patients whose acetabular dysplasia did not show sufficient spontaneous correction at the age of five to six years, or if a tendency to early subluxation was noted.

The lowest rates of avascular necrosis $(2 \%)$ have been reported after gradual closed reduction. ${ }^{5}$ This was confirmed in our series. It is likely that gradual reduction minimises the vascular compromise to the femoral head. Higher rates $\left(3.8 \%\right.$ to $\left.5.8 \%{ }^{18}\right)$ have been reported after acute closed reduction with preliminary traction. $9,18,24$ Overhead traction, as applied by Daoud and Saighi- 
Table III. Radiological outcome based on the Severin ${ }^{12}$ grading system as a function of age, by number and percentage

\begin{tabular}{lrlllll}
\hline & \multicolumn{3}{l}{ Severin grade (\%) } & & & \\
\cline { 2 - 6 } Age (yrs) & I & II & III & IV & p-value \\
\hline 1 to $3(\mathrm{n}=41)$ & $39.0(95.1)$ & $1.0(2.4)$ & 0 & $1(2.4)$ & \\
$>3(\mathrm{n}=6)$ & $2.0(33.3)$ & $2.0(33.3)$ & $1(16.6)$ & $1(16.6)$ & $<0.002$ \\
\hline
\end{tabular}

Table IV. Analysis of published series

\begin{tabular}{|c|c|c|c|}
\hline Author/s & Traction & Severin grade I to II (\%) & $\operatorname{AVN}^{*}(\%)$ \\
\hline \multicolumn{4}{|l|}{ Closed reduction } \\
\hline Ponseti and Frigerio ${ }^{16}$ & No & 74.0 & 12.7 \\
\hline Blockey ${ }^{15}$ & No & 53.0 & 12.0 \\
\hline Williamson et $\mathrm{al}^{34}$ & Yes - acute & 55.0 & Not reported \\
\hline Zionts and MacEwen ${ }^{18}$ & Yes - acute & 82.0 & 5.8 \\
\hline Rengeval et al ${ }^{10}$ & Yes - acute & 60.0 & 5.0 \\
\hline Malvitz and Weinstein ${ }^{19}$ & Yes - acute & 46.0 & 60.0 \\
\hline Schoenecker et $\mathrm{al}^{24}$ & Yes - acute & Not available & 3.8 \\
\hline $\begin{array}{l}\text { Daoud and } \\
\text { Saighi-Bououina }^{25}\end{array}$ & Yes - acute & 80.0 & 10.0 \\
\hline Angliss et $a^{17}$ & Yes - acute & 36.0 & 72.0 \\
\hline Morel $^{5}$ & Yes - gradual & 85.4 & 0.0 \\
\hline Present study & Yes - gradual & 93.6 & 2.1 \\
\hline \multicolumn{4}{|l|}{ Open reduction } \\
\hline Salter and Dubos ${ }^{9}$ & Yes - acute & 93.6 & 5.7 \\
\hline Somerville and Scott ${ }^{3}$ & Yes - acute & 83.0 & Not available \\
\hline Gibson and Benson ${ }^{7}$ & Yes - acute & 46.5 & 5.4 \\
\hline Berkeley et $\mathrm{al}^{21}$ & No & 92.0 & 2.0 \\
\hline Williamson et $\mathrm{al}^{34}$ & Yes - acute & 36.0 & Not reported \\
\hline Galpin et $\mathrm{al}^{26}$ & No & 73.0 & 4.5 \\
\hline Haidar et $\mathrm{al}^{27}$ & No & 83.8 & 8.1 \\
\hline Morcuende et al $^{28}$ & No & 70.0 & 51.0 \\
\hline Olney et $\mathrm{al}^{20}$ & No & 100.0 & 5.5 \\
\hline Huang and Wang 22 & No & 96.8 & 6.2 \\
\hline Angliss et al ${ }^{17}$ & Yes - acute & 20.0 & 88.0 \\
\hline
\end{tabular}

* AVN, avascular necrosis

Bououina $^{25}$ resulted in a rate of avascular necrosis of $10 \%$. The rates reported by Angliss et $\mathrm{al}^{17}$ or Malvitz and Weinstein ${ }^{19}$ were unusually high, because of these authors' strict diagnostic criteria. Rates of avascular necrosis, reaching $12.8 \%$ have been reported after acute closed reduction without preliminary traction. ${ }^{15,16}$ Furthermore, in some studies on closed reduction, avascular necrosis was mostly observed in patients with recurrent dislocation requiring open reduction. ${ }^{18,25}$

Most of the studies on open reduction $7,10,20,22,25,27,28,34$ have reported rates of avascular necrosis which were higher than $5 \%$. This is at least three times higher than those found in our study. This reflects the magnitude of the effect on vascularity of the femoral head which may be created by open reduction. Berkeley et $\mathrm{al}^{21}$ and Galpin et $\mathrm{al}^{26}$ reported lower $(<5 \%)$ rates of avascular necrosis, which could be attributed to the concomitant use of a femoral shortening osteotomy, but they were still higher than those observed after closed reduction. We believe that the tech- nique of gradual closed reduction, as described by Petit et $\mathrm{al}^{4}$ and $\mathrm{Morel}^{5}$ minimises the likelihood of avascular necrosis occurring.

Additional potential drawbacks of open reduction include post-operative stiffness and disuse osteopenia leading to fracture. The latter, although classically attributed to closed reduction, may also occur after open reduction. ${ }^{10}$

Finally, the importance of the age of the patient at the onset of treatment, as a prognostic factor must be emphasised. Children older than three years are less likely to achieve a successful result, as has been reported by Morel. $^{5}$

The improved results obtained with this technique raise expectations for fewer subsequent operations for degenerative osteoarthritis. We consider the Petit-Morel method to be the treatment of choice for children aged between one and five years with DDH.

No benefits in any form have been received or will be received from a commercial party related directly or indirectly to the subject of this article. 


\section{References}

1. Yngve D, Gross R. Late diagnosis of hip dislocation in infants. J Pediatr Orthop 1990;10:777-9.

2. Vallamshetla VR, Mughal E, O'Hara JN. Congenital dislocation of the hip: a preappraisal of the upper age limit. J Bone Joint Surg [Br]2006;88-B:1076-81.

3. Somerville EW, Scott JC. The direct approach to congenital dislocation of the hip J Bone Joint Surg [Br] 1957;39-B:623-40.

4. Petit $\mathbf{P}$, Queneau $\mathbf{P}$, Borde J. Treatment of congenital luxations and subluxations of the hip in early childhood. Rev Chir Orthop Reparatrice Appar Mot 1962;48:148-86 (in French).

5. Morel G. The treatment of congenital dislocation and subluxation of the hip in the older child. Acta Orthop Scand 1975;46:364-99.

6. Severin E. Congenital dislocation of the hip: development of the joint after closed reduction. J Bone Joint Surg [Am] 1950;32-A:507-31.

7. Gibson PH, Benson MKD. Congenital dislocation of the hip. J Bone Joint Surg [Br] 1982;64-B:169-75

8. Coussement A. Repères et mesures en radiodiagnostic. Paris: Expansion scientifique 1974:152-3.

9. Salter RB, Dubos JP. The first fifteen year's personal experience with innominate osteotomy in the treatment of congenital dislocation and subluxation of the hip. Clin Orthop 1974;98:72-103.

10. Rengeval JP, Normand X, Laidi A, Queneau P, Seringe R. Congenital dislocation of the hip treated by the Somerville technique at the age of walking: a long term review. Rev Chir Orthop Reparatrice Appar Mot 1980;66:83-93 (in French).

11. Merle D'Aubigné R. Numerical evaluation of hip function. Rev Chir Orthop Reparatrice Appar Mot 1970;56:481-6 (in French).

12. Severin E. Contribution to the knowledge of congenital dislocation of the hip joint: late results of closed reduction and arthrographic studies of recent cases. Acta Chir Scan 1941;84(Suppl 63):1-142.

13. Kalamchi A, MacEwen GD. Avascular necrosis following treatment of congenital dislocation of the hip. J Bone Joint Surg [Am] 1980;62-A:876-88.

14. Bucholz RW, Ogden JA. Pattern of ischemic necrosis of the proximal femur in nonoperatively treated congenital hip disease. In: The hip. Procs sixth open scientific meeting of the Hip Society. St Louis: CV Mosby, 1978:43-63.

15. Blockey NJ. Derotation osteotomy in the management of congenital hip dislocation. J Bone Joint Surg [Br] 1984;66-B:485-90.

16. Ponseti IV, Frigerio ER. Results of treatment of congenital dislocation of the hip. $J$ Bone Joint Surg [Am] 1959;41-A:823-46.

17. Angliss R, Fujii G, Pickvance E, Wainwright AM, Benson MKD. Surgical treatment of late development displacement of the hip. J Bone Joint Surg [Br] 2005;87B:384-94.

18. Zionts LE, MacEwen GD. Treatment of congenital dislocation of the hip in children between the ages of one and three years. J Bone Joint Surg [Am] 1986;68-A:829-46.
19. Malvitz TA, Weinstein SL. Closed reduction for congenital dysplasia of the hip. $J$ Bone Joint Surg [Am] 1994;76-A:1777-92.

20. OIney B, Latz K, Asher M. Treatment of hip dysplasia in older children with a combined one-stage procedure. Clin Orthop 1998;347:215-23.

21. Berkeley ME, Dickson JH, Cain TE, Donovan MM. Surgical therapy for congenital dislocation of the hip in patients who are twelve to thirty-six months old. J Bone Joint Surg [Am] 1984;66-A:412-20.

22. Huang SC, Wang JH. A comparative study of nonoperative versus operative treatment of developmental dysplasia of the hip in patients of walking age. $J$ Pediatr Orthop 1997;17:181-8.

23. Robert H, Seringe R. Growth disorders of the upper end of the femur following treatment of congenital hip luxation. Rev Chir Orthop Reparatrice Appar Mot 1982;68:425-39 (in French).

24. Schoenecker P, Dollard P, Sheridan J, Strecker W. Closed reduction of developmental dislocation of the hip in children older than 18 months. J Pediatr Orthop 1995; 15:763-7.

25. Daoud A, Saighi-Bououina A. Congenital dislocation of the hip in the older child. J Bone Joint Surg [Am] 1996;78-A:30-40.

26. Galpin RD, Roach JW, Wenger DR, Herring JA, Birch JG. One-stage treatment of congenital dislocation of the hip in older children, including femoral shortening. $J$ Bone Joint Surg [Am] 1989;71-A:734-41.

27. Haidar R, Jones R, Vergroesen D, Evans G. Simultaneous open reduction and Salter innominate osteotomy for developmental dysplasia of the hip. J Bone Joint Surg [Br] 1996;78-B:471-6.

28. Morcuende J, Meyer M, Dolan L, Weinstein S. Long-term outcome after open reduction through an anteromedial approach for congenital dislocation of the hip. $J$ Bone Joint Surg [Am] 1997;79-A:810-17.

29. Kershaw CJ, Ware HE, Pattison R, Fixsen JA. Revision of failed open reduction of congenital dislocation of the hip. J Bone Joint Surg [Br] 1993;75-B:744-9.

30. Thomas SR, Wedge JH, Salter RB. Outcome at forty-five years after open reduction and innominate osteotomy for late-presenting developmental dislocation of the hip. J Bone Joint Surg [Am] 2007;89-A:2341-50

31. Cherney DL, Westin GW. Acetabular development in the infant's dislocated hips Clin Orthop 1989;242:98-103.

32. Lindstrom JR, Ponseti IV, Wenger DR. Acetabular development after reduction in congenital dislocation of the hip. J Bone Joint Surg [Am] 1979;61-A:112-18.

33. Wicart $\mathbf{P}$, Ghanem I, Seringe R. Open reduction after failure of conservative treatment for congenital dislocation of the hip initiated before the age of six months. Rev Chir Orthop Reparatrice Appar Mot 2003;89:115-24 (in French).

34. Williamson DM, Glover SD, Benson MKD. Congenital dislocation of the hip presenting after the age of three years: a long-term review. J Bone Joint Surg [Br] 1989:71-B:745-51. 